\title{
Functional and rheological properties of mixed flour from mangrove fruit of Bruguiera gymnorrhiza flour and wheat flour
}

\author{
1,2,*Amin, M.N.G., ${ }^{2}$ Pebruwantoro, D. ${ }^{2}$ Pralebda, S.A., ${ }^{2}$ Hasan, M.N. ${ }^{2}$ Zakariya, \\ ${ }^{1}$ Subekti, S., ${ }^{1,2}$ Pramono, H. and ${ }^{1}$ Alamsjah, M.A. \\ ${ }^{I}$ Department of Marine, Faculty of Fisheries and Marine, Universitas Airlangga, Mulyorejo, Surabaya, East \\ Java 60115 Indonesia \\ ${ }^{2}$ Undergraduate Program of Aquaculture, Majoring in Fisheries Product Industrial Technology, Faculty of \\ Fisheries and Marine, Universitas Airlangga, Mulyorejo, Surabaya, East Java 60115 Indonesia
}

\author{
Article history: \\ Received: 13 July 2020 \\ Received in revised form: 10 \\ August 2020 \\ Accepted: 8 September 2020 \\ Available Online: 12 \\ December 2020
}

\section{Keywords:}

BGF,

Wheat flour,

Viscosity

DOI:

https://doi.org/10.26656/fr.2017.5(1).356

\begin{abstract}
In order to yield influential information on the most recommended use of BGF, which so far still questioned, this preliminary study was aimed to investigate the physicochemical and functional properties of mixed flour of BGF and wheat flour (WF). A total of nine mixtures of WF: BGF of (90\%:10\%; $80 \%: 20 \% ; 70 \%: 30 \% ; 40 \%: 60 \% ; 50 \%: 50 \%$; 40\%:60\%; 30\%:70\%; 20\%:80\%; 10\%:90\%) were produced, where single WF and BGF were used as controls. This research revealed the different amount of BGF and wheat flour in the mixed flour showed the significantly different value of functional and rheological properties attributes, such as bulk density, CI, HR, WAI, WSI, SP, OAC, peak viscosity, trough viscosity, breakdown viscosity, final viscosity, setback viscosity and peak time. We have inferred to some previous studies and speculated that the difference in functional and rheological properties could be caused by the different amylose and amylopectin amount in the mixed flour. As far as we know that this present study was the first study on the mixed flour of BGF and wheat flour, therefore we suggested a more comprehensive study such as investigation of baking performance and bread qualities.
\end{abstract}

\section{Introduction}

Bruguiera gymnorrhiza flour (BGF) is a growing mangrove species that is widely distributed in the tropics and occurs along the east coast of Africa from just north of East London (Eastern Cape) to Somalia, Madagascar and the Indian Ocean islands, the south Asian coast from Iran to China, north Australia and numerous tiny (and larger) islands in the Pacific (South African National Biodiversity Institute). In fact, this species has been utilized by many coastal people to some value-added products such as flour, crackers and flatbread or biscuit. Our observation prior this present study represented that the particle size of BGF produced by people was relatively too large; consequently, BGF could not be mixed well with other ingredients in bread making, which further causes poor consistency of the final product. This problem is due to the lack of scientific proof on the functional and rheological characteristics on the mixed flour. A previous study by Amin et al. (2018) shows that BGF is cohesive, has a small amount of protein, and is suggested to be mixed with wheat flour with a low protein amount for biscuit making. Generally, there are some ideas of mixing different flour such as fortification purposes, cost-effectiveness, emerging supply chain problem towards wheat flour and intensify the customer preferences (Khetarpaul and Goyal, 2009; Udofia et al., 2013; Iwe et al., 2016).

Previous studies demonstrate that the different flour mixed in the bread recipe could yield different physicochemical, functional and sensory characteristics of the final bread produced (Chandra et al., 2015), where generally bread producers are willing to produce bread with high customer preferences. Monthe et al. (2019) and Ren et al. (2020) demonstrate that the different final characteristics of the bread produced from different flour are caused by the different functional and rheological properties of the blended flour in the recipe. Therefore, this idea became the main approach to performing this present study.

Functional properties of the flour are related to density, swelling capacity, water absorption index (WAI), water solubility index (WSI), oil absorption capacity (OAC), emulsifying activity and foaming 
capacity (Prajapati et al., 2015; Menon et al., 2015), while rheological properties are related to peak viscosity, trough viscosity, breakdown viscosity, final viscosity, setback viscosity, peak time and pasting temperature (Jariyah et al., 2014; Gerits et al., 2015; Shafie et al., 2016). The rapid visco-analyzer (RVA) is a robust method which is incredibly useful in the flour studies. This method possesses by mimicking the cooking process of a cereal when a flour-water suspension is subjected to a heat-hold-cool-hold temperature cycle (Chen et al., 2008). Our present study aims to investigate the functional and rheological properties of mixed flour from wheat flour and BGF.

\section{Material and methods}

\subsection{Materials}

Two main flour were used in this study vis. wheat flour and Bruguiera gymnorrhiza flour (BGF). Wheat flour with the total fat, protein, carbohydrate, starch, amylose, and the ratio of amylose to starch of $1.00 \%(\mathrm{w} /$ $\mathrm{w}), \quad 10 \% \quad(\mathrm{w} / \mathrm{w}), \quad 76 \% \quad(\mathrm{w} / \mathrm{w}), 63.41 \pm 0.11 \% \quad(\mathrm{w} / \mathrm{w})$, $23.85 \pm 0.41 \%(\mathrm{w} / \mathrm{w})$ and $24: 76$ respectively was obtained from PT. Bogasari Tbk. Indonesia. BGF with the total starch, amylose, and ratio of amylose to starch of $59.15 \pm 1.52 \%(\mathrm{w} / \mathrm{w}), \quad 34.30 \pm 2.55 \%(\mathrm{w} / \mathrm{w})$ and $34: 66$ respectively was prepared by Amin et al. (2018) with a very slight modification, where the milling was conducted more intensively by using a stainless steel flour miller FCT Z100. Mixed flours were prepared by a physically mixing of two different flours until fully homogenous, with eventually nine combinations were made with two single flours such as wheat flour and BGF which were used as controls (Table 1).

\begin{tabular}{ccc}
\multicolumn{3}{c}{ Table 1. Formulation of mixed flour } \\
\hline Code & Wheat flour $(\% \mathrm{w} / \mathrm{w})$ & BGF $(\% \mathrm{w} / \mathrm{w})$ \\
\hline A & 100 & 0 \\
B & 90 & 10 \\
C & 80 & 20 \\
D & 70 & 30 \\
E & 60 & 40 \\
F & 50 & 50 \\
G & 40 & 60 \\
H & 30 & 70 \\
I & 20 & 80 \\
J & 10 & 90 \\
K & 0 & 100 \\
\hline
\end{tabular}

\subsection{Proximate composition determination}

Moisture content, fat content, amylose content, total starch was analyzed using the reference methods of AOAC (2007). Carbohydrate content was determined by using by difference method.
2.3 Determination of density, expansion index, Carr index and Hausner ratio

The density was determined according to a method of Okezie and Bello (1988) which was prior used by Amin et al. (2018). Hausner ratio and Carr index were analyzed using this following equation:

$$
\begin{aligned}
& \text { Hausner ratio }(\mathrm{HI})=\frac{\text { Tapped density }(\mathrm{g} / \mathrm{mL})}{\text { Bulk density }(\mathrm{g} / \mathrm{mL})} \\
& \text { Carr Index }(\mathrm{CI})=\frac{\text { Tapped density }(\mathrm{g} / \mathrm{mL})-\text { Bulk density }(\mathrm{g} / \mathrm{mL})}{\text { Tapped density }(\mathrm{g} / \mathrm{mL})} \times 100
\end{aligned}
$$

Flour with $\mathrm{HR}<1.2,1.2<\mathrm{HR}<1.4,>1.4$ is classified as low, intermediate, high cohesive group respectively, while $\mathrm{CI}<15,15<\mathrm{CI}<20,20<\mathrm{CI}<35,>45$ is classified as very good, fair, bad, very bad respectively

\subsection{Gel hydration properties}

Gel hydration properties were performed according to Toyokawa et al. (1989). Approximately $100 \mathrm{mg}$ of flour $\left(\mathrm{W}_{\mathrm{i}}\right)$ was dispersed in $2.0 \mathrm{~mL}$ of water and then heated at the temperature of $90^{\circ} \mathrm{C}$ for 10 mins in a thermostat water bath. The suspension was then cooled at the temperature of $4^{\circ} \mathrm{C}$, centrifuged at $3,500 \mathrm{rpm}$ for 15 mins. The supernatant was decanted and then evaporated with an oven at the temperature of $105^{\circ} \mathrm{C}$ until the sample shows a persistent weight $\left(\mathrm{W}_{\mathrm{s}}\right)$. The residue (lower fraction of centrifuged sample) was also weighed $(\mathrm{Wr})$. The result was calculated according to the following equations:

$$
\begin{aligned}
& \text { WAI }\left(\frac{\mathrm{g}}{\mathrm{g}}\right)=\frac{\mathrm{Wr}_{\mathrm{r}}}{\mathrm{Wi}_{\mathrm{i}}} \\
& \text { WSI }\left(\frac{\mathrm{g}}{\mathrm{g}}\right)=\frac{\mathrm{W}_{\mathrm{s}} \times 100}{\mathrm{Wi}_{\mathrm{i}}} \\
& \text { SP }\left(\frac{\mathrm{g}}{\mathrm{g}}\right)=\frac{\mathrm{Wr}_{\mathrm{r}}}{\mathrm{Wi}_{\mathrm{i}}-\mathrm{W}_{\mathrm{s}}}
\end{aligned}
$$

\subsection{Oil absorption capacity $(O A C)$}

A $100 \mathrm{mg}$ of flour was weighed $\left(\mathrm{W}_{\mathrm{i}}\right)$, mixed with 1 $\mathrm{mL}$ vegetable oil, then the mixture was vortexed for 2 mins with maximum velocity. The mixture was then centrifuged at $3000 \mathrm{rpm}$ for $10 \mathrm{mins}$, the supernatant was decanted. The tube containing residue was then inverted to remove remaining oil in the flour, furthermore the residue was weighed $\left(\mathrm{W}_{\mathrm{r}}\right)$ and then the $\mathrm{OAC}$ was determined according to the following equation.

$$
\begin{aligned}
& \mathrm{OAC}\left(\frac{\mathrm{g}}{\mathrm{g}}\right)=\frac{\mathrm{W}_{\mathrm{r}}}{\mathrm{W}_{\mathrm{i}}} \\
& 2.6 \text { Rheological properties determination }
\end{aligned}
$$

\subsection{Rheological properties determination}

Rheological properties were determined by using a Rapid Visco Analyzer (RVA-4, Newport Scientific Pty Ltd., Warriewood, NSW2102, Australia). A $2.5 \mathrm{~g}$ of flour was dispersed in $25 \mathrm{~mL}$ water in an aluminum can and then the suspension was centrifuged at $160 \mathrm{RPM}$ at the temperature of $50^{\circ} \mathrm{C}$ for $1 \mathrm{~min}$. The heating was then raised to $95^{\circ} \mathrm{C}$ within 7.5 mins and held at $95^{\circ} \mathrm{C}$ for 5 mins, and then cooled back to $50^{\circ} \mathrm{C}$ within 7.5 mins and 
held at $50^{\circ} \mathrm{C}$ for additional 2 mins (Rahmawati et al., 2014).

\subsection{Statistical analysis}

One-way analysis of variance (ANOVA) furthered by Tukey's HSD (honestly significant difference) were carried out by using a Statistical Software SPSS 16. The statistical analyses were performed with a confidence level of $95 \%$.

\section{Results and discussion}

3.1 Moisture content and functional properties of mixed flour from wheat flour and $B G F$

The analysis of variance showed that moisture content within observed flours was not affected by the formulation (Table 2). This happened because the moisture content between control wheat flour and BGF was quite similar. While all functional properties variables, apart from tapped showed a significant difference.

Table 2. Analysis of variance (ANOVA) results

\begin{tabular}{lcc}
\hline Variables & F-value & ${ }^{*}$ p-value \\
\hline Moisture content & 1.661 & 0.154 \\
Functional properties & & \\
Tapped density & 1.187 & 0.351 \\
Bulk density & 53.288 & 0.000 \\
CI & 10.928 & 0.000 \\
HR & 18.426 & 0.000 \\
WAI & 4.004 & 0.003 \\
WSI & 8.161 & 0.000 \\
SP & 2.923 & 0.017 \\
OAC & 23.293 & 0.000 \\
Rheological properties & & \\
Peak viscosity & $1.69 \mathrm{E}+03$ & 0.000 \\
Trough viscosity & 271.057 & 0.000 \\
Breakdown viscosity & $1.02 \mathrm{E}+03$ & 0.000 \\
Final viscosity & 949.392 & 0.000 \\
Setback viscosity & 527.423 & 0.000 \\
Peak time & 234.242 & 0.000 \\
Pasting temperature & 1.387 & 0.299 \\
\hline
\end{tabular}

*A significant $\mathrm{p}$-value was $(\leq 0.05)$

According to Table 3, the mixed flour with more BGF relatively had lower tap density because BGF, while the highest cohesiveness and flow-ability were mixed flour "C" and "I" respectively. Particle size and the ratio of amylase and amylopectin were the crucial factors affecting these characteristics, where amylopectin has a bigger molecular weight than amylose. Abdullah and Geldart (1999) state that flour with good flow-ability could be produced by reducing the consolidation ability with each other. Fitzpatrick (2005) states that the surface area of the flour affects the particle contact, cohesive force and frictional forces where flour with the lower particle size will more attractive to contact with each particle to resist flow. This study suggested that in the industrial application, mixed flour with a high bulk density would relatively require spaces during storage.

Gel hydration is a highly important variable in the future application of mixed flours in this present study. WSI, WAI and swelling power has correlation each other, where according to the equation the value of swelling power depends on the number of water-soluble fractions and the capacity of the flour in absorbing water during the gelatinization. This research showed that single BGF had lower swelling power than wheat flour, and the incorporation of BGF in mixed flour relatively decreased the swelling power of the mixed flour (Table 3). According to Bhat et al. (2016), gel hydration properties of the flour is related to the ratio of amylose and amylopectin, where flour with more amylopectin binds more water than flour with lower of amylopectin. The increase of WSI when more BGF incorporated in the mixed flour could demonstrate that BGF theoretically had more water-soluble fraction such as tannin (Girard $e t$ al., 2018), tannin can interact with a protein of the flour where the interaction decreases the surface hydrophobicity of flour protein (gluten). Wang et al. (2015) state that the decreasing of surface hydrophobicity of the gluten because of tannin-induced gluten polymer aggregation. According to Yang et al. (2017), the decreasing of surface hydrophobicity of flour protein can influence the capacity of the protein in absorbing water and oil.

The oil absorption capacity (OAC) is considered important for the future use of mixed flour in this study, as bakery products contain some butter to yield palatable bread. This study represented that BGF relatively increased the oil absorption capacity of the mixed flour (Table 3). Gerits et al. (2015) reveal that amylose can bind lipid more than amylopectin, which means the flour containing more amylose tends to bind more lipid than flour with less amylose content. Niba et al. (2001) state that flour having high oil absorption capacity is suitable to be used in baking because it can improve mouthfeel and maintain the flavor of the baking product.

\subsection{Rheological properties of mixed flour}

Based on the statistical analysis, most rheological properties were significantly affected by the ratio of wheat flour to BGF, although only pasting temperature was not significantly affected by the formulation (Table 2).

According to Table 4 peak viscosity of the mixed flour reduced when BGF was incorporated, this finding was speculated due to the reduction of theoretical protein of the mixed flour as the consequence of BGF 
incorporation. Protein should be responsible for trapping water; meanwhile, the content was practically reduced due to incorporation (Hamer and Hoseney, 1998). Furthermore, peak viscosity is related to the waterbinding capacity of the flour, where reduction of peak viscosity indicates declining swelling or gelatinization power (Beta and Corke, 2001). More specifically, water binding capacity also depends on the ratio of amylose to amylopectin, where amylopectin has a better capability in binding water.

Apart from peak viscosity, final, setback, breakdown viscosity relatively declined when BGF was incorporated. This phenomenon could be connected to a prior study by Sopade et al. (2006) that states the capability of forming gel affects the final viscosity. Hence, this study concluded that the more BGF, the lower amount of gels formed in the mixed flour. Setback viscosity is related to the flour retro-gradation where flour with low setback viscosity implies the high resistance to retro-gradation (Ikagewu et al., 2009). According to Ikegwu et al. (2009), flour with low setback viscosity has resistance in starch retro-gradation. A prior study carried out by Jariyah et al. (2014) suggests that flour with high resistance in starch retrogradation is recommended to be incorporated into baked food ingredients.

The declining of breakdown viscosity was relevant to Corke et al. (2017), showing that flour paste with low breakdown viscosity has low hydration ability, swelling power and high sear resistance. This present study also revealed that the incorporation of BGF into mixed flour relatively reduced WAI and SP. The lower breakdown viscosities may be due to restricted swelling of the starch granules, which increase the tendency of the hydrophilic chain of flour containing fiber to bind with hydrogen bonds of the water. Furthermore, the reduced water availability for starch granules occurs.

The pasting temperature was different within composition where according to Fitzgerald et al. (2003). The decreasing of moisture content increases of pasting temperature, suggesting that water affects the rheological responses to stirring of the components of the gelatinized and swollen flour. Shafie et al. (2016) state that the higher pasting temperature indicates the resistance against swelling in the ingredient, which could be correlated to the amount of amylose and amylopectin in the flour.

To the best of our knowledge, the present work is the first study to focus on the characterizing the mixture of BGF with wheat flour, which meant a more comprehensive study on the mixed flour is necessary such investigation of baking performance and bread qualities.

\section{Conclusion}

This research revealed the different amount of BGF and wheat flour in the mixed flour showed the significantly different value of functional and rheological properties attributes, such as bulk density, CI, HR, WAI, WSI, SP, OAC, peak viscosity, trough viscosity, breakdown viscosity, final viscosity, setback viscosity and peak time. We have inferred to some previous studies and speculated that the difference in functional and rheological properties could be caused by the different amylose and amylopectin amount in the mixed flour. As far as we know that this present study was the first study on the mixed flour of BGF and wheat flour, therefore we suggested a more comprehensive study such as investigation of baking performance and bread qualities.

\section{Conflict of interest}

There is no conflict of interest

\section{Acknowledgement}

Thanks to Faculty of Fisheries and Marine Universitas Airlangga for the Annual Research Grant through Rencana Kerja Anggaran Tahunan (RKAT) for Research Scheme 2017. Thanks to Ristyananda Refian Hidayatullah who helped us in interpreting the statistical analysis in this study

\section{References}

Abdullah, E.C. and Geldart, D. (1999). The use of bulk density measurements as flowability indicators. Powder Technology, 102(2), 151-165. https://doi.org/10.1016/S0032-5910(98)00208-3

Amin, M.N.G., Pralebda, S.A., Hasan, M.N., Zakariya, Subekti, S., Saputra, E, Andriyono, S., Pramono, H. and Alamsjah, M.A. (2018). Physicochemical properties of Bruguiera gymnorrhiza flour (BGF). International Food Research Journal, 25(5), 1852-1857.

Beta, T. and Corke, H. (2001). Noodle quality as related to sorghum starch properties. Cereal Chemistry, 78 (4), 417- 420. https://doi.org/10.1094/ CCHEM.2001.78.4.417

Bhat, N.A., Wani, I.A., Hamdani, A.M., Gani, A. and Masoodi FA. (2016). Physicochemical properties of whole wheat flour as affected by gamma irradiation. LWT - Food Science and Technology, 71, 175-183. https://doi.org/10.1016/j.lwt.2016.03.024

Chandra, S., Singh, S. and Kumari, D. (2015). 
Evaluation of functional properties of composite flours and sensorial attributes of composite flour biscuits. Journal of Food Science and Technology, 52, 3681-3688. https://doi.org/10.1007/s13197-014$1427-2$

Chen M.H., Bergman, C.J., Pinson, R.M. and Fjellstrom, R.G. (2008) Waxy genehaplotypes: associations with pasting properties in an international rice germplasm collection. Journal of Cereal Science, 48(3), 781788. https://doi.org/10.1016/j.jcs.2008.05.004

Corke, H., Wu, H., Yue, S. and Sun, H. (1997). Developing Specialty Starches from New Crops: A Case Study Using Grain Amaranth. In Campbell, G.M., Webb, C. and McKee, S.L. (Eds.) Cereals: Novel Uses and Processes, p. 95-100. Boston, Massachusetts: $\quad$ Springer. doi.org/10.1007/978-1-4757-2675-6_12

Fitzgerald, MA., Martin, M., Ward, R.M., Park, W.D. and Shead, H.J. (2003). Viscosity of rice flour: a rheological and biological study. Journal of Agriculture and Food Chemistry, 51, 2295-2299. https://doi.org/10.1021/jf020574i

Fitzpatrick, J., Barry, K., Delaney, C. and Keogh, K. (2005). Assessment of the flow-ability of spray-dried milk powders for chocolate manufacture. Dairy Science and Technology, 85(4-5), 269-277. https:// doi.org/10.1051/lait:2005012

Gerits, L.R., Pareyt, B. and Delcour, J.A. (2015). Wheat starch swelling, gelatinization and pasting: Effects of enzymatic modification of wheat endogenous lipids. LWT - Food Science and Technology, 63(1), 361366. https://doi.org/10.1016/j.lwt.2015.02.035

Girard, A.L., Bean, S.R., Tilley, M., Adrianos, S.L. and Awika, J.M. (2018). Interaction mechanisms of condensed tannins (proanthocyanidins) with wheat gluten proteins. Food Chemistry, 245, 1154-1162. https://doi.org/10.1016/j.foodchem.2017.11.054

Hamer, R.J. and Hoseney, R.C. (1998). Interactions-the keys to cereal quality. St Paul, Minnesota, USA: American Association of Cereal Chemists.

Ikegwu, O.J., Nwobasi, V.N., Odoh, M.O. and Oledinma, N.U. (2009). Evaluation of the pasting and some functional properties of starch isolated from some improved cassava varieties in Nigeria. African Journal of Biotechnology, 8, 2310-2315.

Iwe, M.O., Onyeukwu, U. and Agiriga, A.N. (2016). Proximate, functional and pasting properties of FARO 44 rice, African yam bean and brown cowpea seeds composite flour. Cogent Food and Agriculture, $2, \quad 1142409$. doi.org/10.1080/23311932.2016.1142409
Jariyah, J., Widjanarko, S., Yunianta, Estiasih, T. and Sopade, P. (2014). Pasting properties mixtures of mangrove fruit flour (Sonneratia caseolaris) and starches. International Food Research Journal, 21 (6), 2161-2167.

Khetarpaul, N. and Goyal, R. (2009). Effect of composite flour fortification to wheat flour on the quality characteristics of unleavened bread. British Food Journal, 111(6), 554-564. https:// doi.org/10.1108/00070700910966014

Menon, L., Majumdar, S.D. and Ravi, U. (2015). Development and analysis of composite flour bread. Journal of Food Science and Technology, 52, 41564165. https://doi.org/10.1007/s13197-014-1466-8

Monthe, O.C., Grosmaire, L., Nguimbou, R.M., Dahdouh, L., Ricci, J., Tran, T. and Ndjouenkeu, R. (2019). Rheological and textural properties of gluten -free doughs and breads based on fermented cassava, sweet potato and sorghum mixed flours. LWT - Food Science and Technology, 101, 575-582. https:// doi.org/10.1016/j.lwt.2018.11.051

Niba, L.L., Bokonga, M.M., Jackson, E.L., Schlimme, D.S. and Li, B.W. (2001). Physicochemical properties and starch granular characteristics of flour from various Manihot esculenta (cassava) genotypes. Journal of Food Science, 67(5), 1701-1705. https:// doi.org/10.1111/j.1365-2621.2002.tb08709.x

Prajapati, R., Chandra, S., Samsher, N.C., Singh, G.R. and Kumar, S. (2015). Effect of incorporation of flours on the functional properties of composite flours. South Asian Journal of Food Technology and Environment, 1, 233-241. https://doi.org/10.46370/ sajfte.2015.v01i03and04.05

Rahmawati, F., Hariyadi, P., Fardiaz, D. and DewantiHariyadi, R. (2014). Pasting properties of white corn flours of Anoman 1 and Pulut Harapan varieties as affected by fementation process. Food and Nutrition Sciences, 5, 2038-2047. https://doi.org/10.4236/ fns.2014.521215

Ren, Y., Linter, B.R., Linforth, R. and Foster, T.J. (2020). A comprehensive investigation of gluten free bread dough rheology, proving and baking performance and bread qualities by response surface design and principal component analysis. Food and Function, 11(6), 5333-5345. https://doi.org/10.1039/ D0FO00115E

Shafie, B., Cheng, S.C., Lee, H.H. and Yiu, P.H. (2016). Characterization and classification of whole-grain rice based on rapid visco analyzer (RVA) pasting profile. International Food Research Journal, 23(5), 2138-2143.

Sopade, P.A., Hardin, M., Fitzpatrick, P., Desmee, H. 
and Halley, P. (2006). Macromolecular interactions during gelatinization and retrogradation in starch whey systems as studied by Rapid Visco-Analyser. International Journal of Food Engineering, 2(4), 115. https://doi.org/10.2202/1556-3758.1074

Toyokawa, H., Rubenthaler, G., Powers, J. and Schanus, E. (1989). Japanese noodle qualities flour components. Cereal Chemistry, 66, 382-386.

Udofia, P.G., Udoudo, P.J. and Eyen, N.O. (2013). Sensory evaluation of wheat-cassava-soybean composite flour (WCS) bread by the mixture experiment design. African Journal of Food Science, 7(10), 368-374. https://doi.org/10.5897/AJFS09.108

Wang, Q., Li, Y., Sun, F., Li, X., Wang, P., Sun, J., Zeng, J., Wang, C., Hu, W., Chang, J., Chen, M., Wang, Y., Li, J., Yang, G. and He, G. (2015). Tannins improve dough mixing properties through affecting physicochemical and structural properties of wheat gluten proteins. Food Research International, 69, 64-71. https://doi.org/10.1016/ j.foodres.2014.12.012

Yang, S., Jia, Z., Ouyang, X., Bai, H. and Liu, R. (2017). Hydrophobicity characteristics of algae-fouled HVDC insulators in subtropical climates. Electric Power Systems Research, 163(Part B), 626-637. https://doi.org/10.1016/j.epsr.2017.11.009 